RICYDE. Revista Internacional de Ciencias del Deporte doi: $10.5232 /$ ricyde

Rev. int. cienc. deporte

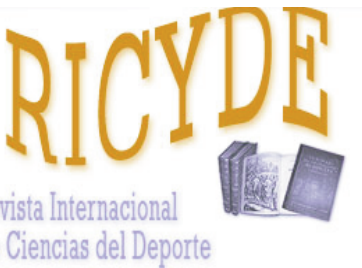

RICYDE. Revista Internacional de Ciencias del Deporte VOLUME XIV - YEAR XIV

Pages:219-232 ISSN:1885-3137

Issue: 53 - July - 2018

\title{
Intra-seasonal variation of anthropometrical, conditional, and technical tests in U14 soccer players \\ Variación en los parámetros antropométricos, condicionales y test técnicos de jugadores de fútbol SUB-14
}

\author{
Fabio Massimo Francioni ${ }^{1}$, Antonio José Figueiredo ${ }^{2}$, Corrado Lupo ${ }^{3}$, Marco Terribili4, \\ Giancarlo Condello ${ }^{1}$ \& Antonio Tessitore ${ }^{1}$
}

\begin{abstract}
1.Department of Movement, Human and Health Sciences, University of Rome "Foro Italico", Rome. Italy 2.Faculty of Sport Sciences and Physical Education, University of Coimbra, Coimbra. Portugal

3.School of Exercise \& Sport Sciences (SUISM), Department of Medical Sciences, University of Torino, Turin. Italy

4.Istat, Italian National Institute of Statistics, Rome. Italy
\end{abstract}

\begin{abstract}
This study aimed to analyze the annual variation of soccer players abilities assessed by means of a field-battery test administered six times during an entire competitive season (from T0 to T5). Anthropometric (i.e., body mass, stature, and body mass index), soccer skill (i.e., touch with the body, touch with the head, passing, shooting, dribbling with pass, and dribbling) and functional capacities (i.e., counter-movement jump with and without free arms, and speed) tests were submitted to 33 Under-14 soccer players. A general improvement across the season as confirmed by the rising effects from 0.3 (T2) to 0.6 (T5) was showed. The technical skills (except touch with the head and dribbling) and functional tests showed significant differences $(p<0.001)$ between T0 and T5 but they were not dependent by the exposure to training. This study underlined that the skills' development in youth soccer players are not linear due to the effects of the growth and maturation. In order to optimize this process, in-season assessment are needed. Finally, programs and decisions promoted by coaches and scouts aimed to the development of youth soccer players should be inspired by the potential results that might be achieved by players.
\end{abstract}

Key words: youth football; talent identification; longitudinal studies; physical performance.

\section{Resumen}

El objetivo del presente estudio consistió en analizar la variación anual de las habilidades de jugadores de fútbol sub-14 ( $n=33)$ mediante una batería de test de campo administrados seis veces a lo largo de la temporada (de T0 a T5). Las mediciones registradas se centraron en aspectos antropométricos (i.e., talla, peso e índice de masa corporal), habilidades específicas (i.e., toques con el cuerpo, con la cabeza, pases, lanzamientos, regates con pase y regates) y la condición física (i.e., salto en contra movimiento con y sin movimiento de brazos y velocidad). Los resultados mostraron una mejora a lo largo de la temporada con efectos que pasaron de 0.3 (T2) a 0.6 (T5). Las habilidades técnicas (excepto el toque con la cabeza y el regate) y los test funcionales mostraron diferencias significativas $(p<0.001)$ entre los periodos T0 y T5, pero éstas no fueron dependientes de la exposición al entrenamiento. El presente estudio permite resaltar que el desarrollo de habilidades en jóvenes jugadores de fútbol no es lineal debido a los efectos del desarrollo y la maduración. En relación con el proceso de optimización de entrenamiento se requieren evaluaciones a lo largo de la temporada. Finalmente, los programas específicos y las decisiones de entrenadores y scouters debe centrarse en el desarrollo de los jugadores jóvenes tomando como punto de partida el potencial que pueden alcanzar.

Palabras clave: fútbol; identificación de talentos; estudios longitudinales; rendimiento físico.

Correspondence/correspondencia: Fabio Massimo Francioni

Department of Movement, Human and Health Sciences, University of Rome "Foro Italico", Rome. Italy

Email: fmfrancioni@hotmail.it 
Francioni, F. M.; Figueredo, A. J.; Lupo, C.; Terribili, M.; Condello, G., \& Tessitore, A. (2018). Intra-seasonal variation of anthropometrical, conditional, and technical tests in U14 soccer players. RICYDE. Revista internacional de ciencias del deporte, 53(14), 219-232. https://doi.org/10.5232/ricyde2018.05303

\section{Introduction}

$\mathrm{I}$ n soccer, the talent identification and developmental (TID) programs are largely increased during the last two decades, with the primary aim to identify which factors can be really determinant to turn the player's potential to rise to higher levels of play (Abbott and Collins, 2004; Elferink-Gemser, Visscher, Lemmink and Mulder, 2007; Le Gall, Carling, Williams and Reilly, 2010; MacNamara and Collins, 2011; Reilly, Williams and Neville, 2000; Vaeyens, Malina, Janssens, Van Renterghem, Bourgois, Vrijens and Philippaerts, 2006). For this reason, sports scientists and coaches should cooperate sharing their specific knowledge to improve the applicability and interpretation of the entire TID process (Lidor, Còtè and Hackfort, 2009). In particular, Reilly et al. (2000) have first supported the usefulness of field-test batteries as a tool to assess the specific influence of technical (Figueiredo, Goncalves, Coelho-e-Silva and Malina, 2009; Malina, Cumming, Kontos, Eisenmann, Ribeiro and Aroso, 2005; Rosch, Hodgson, Peterson, Graf-Baumann, Junge, Chomiak and Dvorak, 2000), conditional and physiological (Le Gall et al., 2010), anthropometrical (Carling et al, 2009) and psychological (Holt, Mitchell and Button, 2006) individual characteristics of young soccer players, as well as the potential interaction of all these aspects (Meylan, Cronin, Oliver and Hughes, 2010).

In general, the evaluation of the effectiveness of TID programs involving athletes between 13 and 15 years old can be complicated by their maturation and growth status. Indeed, these factors could determine an instable development of the individuals' fundamental characteristics, which can be confused during an early selection (Williams et al., 2000). However, previous studies investigating the relationship between maturity and sport-specific skills in young soccer players aged 13-15 yrs (Malina et al., 2009) and 11-14 yrs (Figueiredo et al., 2009) showed a little variation of performance due to their age, experience, body size and stage of puberty, suggesting as other factors (e.g. perceptual-cognitive skills such as anticipation and visual search strategies and neural control of movement) may influence the performance of specific sport-skill tests. In fact, high level of sport-specific skills could compensate potential disadvantages of performance given by body size dimensions of delayed-maturity players (Williams et al., 2000). Furthermore, the evaluation through field-test batteries can predict only short terms training effects, while from a short- and long-term perspective the conditions for sports success can be even contrary as far as their contents are concerned and reverse in their opposite in a longer period (Gullich and Emrich, 2006). Thus, to substantiate this aspect several authors have highlighted the limitation of those TID programs where players are selected mainly for their physical (conditional) performances (Gullich and Emrich, 2006; MacNamara, Buttan and Collins, 2010a; Reilly et al., 2000). In fact, compared with other sports (i.e. individual sports) an early success of team sport players is less likely to be evident in presence of a low level of the necessary technical and tactical skills to engage successfully (MacNamara, Buttan and Collins 2010b).

Regarding the literature provided on soccer players' talent identification, it could be classified in three main groups in relation to the experimental design adopted: i) studies that investigate differences of performance between a pre- and post-cycle of training or competition involving the same age-category; ii) studies exploring the age-related differences in terms of performance; iii) studies that analyze differences between different players' technical levels. For the first group (regarding the same age-category) the results obtained after a training period frequently show a general improvement of players' skills due to the double effects of training exposure and experience (Helsen, Van Winckel and Williams, 2005). 
Francioni, F. M.; Figueredo, A. J.; Lupo, C.; Terribili, M.; Condello, G., \& Tessitore, A. (2018). Intra-seasonal variation of anthropometrical, conditional, and technical tests in U14 soccer players. RICYDE. Revista internacional de ciencias del deporte, 53(14), 219-232. https://doi.org/10.5232/ricyde2018.05303

Instead, comparing different age-categories several studies have documented better results, for instance in terms of speed, for older well-trained players during the adolescence (Miranda, Antunes, Pauli, Puggina and Da Silva, 2013), as well as for strength, anthropometric and anaerobic capacities in earlier matured players (Malina et al., 2005; Mendez-Villanueva, Buchheit, Kuitunen, Douglas, Peltola and Bourdon, 2011).

In general, skills are more difficult to measure compared to physiological aspects, such as speed and power (Malina et al., 2005), provoking a contradictory interpretation of results by sports scientists. For instance, academy players showed significant differences for ball control and dribbling performance respect their level of elite sub-elite and non-elite players (Vaeyens et al., 2006), but not when they were assessed based on their late- average- early-maturity status (Figueiredo et al., 2009a). However, these claims should not discourage coaches and clubs to give an opportunity to smaller and/or late mature players that could obtain success by compensative abilities.

Although the related literature on soccer skills is mainly provided by cross-sectional studies, these can be considered as a "snapshot" that show differences between players of different ages and levels, while a mixed-longitudinal approach is considered to be essential to assess the fluctuations of players' dynamic abilities (Francioni, Figueiredo, Terribili and Tessitore, 2016; Vaeyens et al., 2006, Unnithan, White, Georgiou, Iga and Drust, 2012). Therefore, the overall purpose of this study was to assess the variations of results of anthropometrical, technical and physical tests in young soccer players by means of an annual longitudinal approach based on several measurements (tests sessions) taken during the same season. Furthermore, to analyze the relationship between each variation of tests' results (given by the difference between two successive test sessions) and the amount of training time spent during these periods. It was assumed that players should have shown a constant improvement of all variables with the lowest and the best values at the beginning end at the end of the season, respectively.

\section{Methodology}

A field-test battery was submitted with a regular interval of two months (six times in total) during the soccer season [T0: August (before the start of the season); T1: October; T2: December; T3: February; T4: April; T5: June (end of season)] to all young players recruited for this study. Consequently, for all players were planned five periods of training ( $\mathrm{P} 1$ from $\mathrm{T} 0$ to T1; P2 from T1 to T2; P3 from T2 to T3; P4 from T3 to T4; P5 from T4 to T5). Thus, the time of training (minutes) spent during each period was registered by means of a training log, in order to quantify the following parameters: a) time spent to develop technical and tactical skills; b) time spent to develop conditional capacities. Furthermore, chronological age, stature (to the nearest $0.1 \mathrm{~cm}$ ), and body mass (to the nearest $0.1 \mathrm{~kg}$ ) of each player were measured by means of a formula using date of birth and the date of test sessions (Malina et al., 2005), a stadiometer (Seca $702^{\circledR}$, Hamburg, Germany) and a balance (Joycare, JC-434 B/W ${ }^{\circledR}$, Chiaravalle, Italy), respectively.

\section{Participants}

Thirty-three male young soccer players (with at least 5 yrs of academy experience) from the same Under 14 league (13 and 14 yrs old) were initially recruited for this study. All players belonged to two clubs (US Fermana, $n=15$; and AFC Fermo, $n=18$ ). The reason to collect data from the two clubs was given by the fact that they had the same ownership, training facilities, technical direction and annual activity planning (number of training units and matches). 
Francioni, F. M.; Figueredo, A. J.; Lupo, C.; Terribili, M.; Condello, G., \& Tessitore, A. (2018). Intra-seasonal variation of anthropometrical, conditional, and technical tests in U14 soccer players. RICYDE. Revista internacional de ciencias del deporte, 53(14), 219-232. https://doi.org/10.5232/ricyde2018.05303

The usual weekly plan was based on three training sessions (i.e., Tuesday, Thursday and Friday) with one official game every Sunday morning. Each training session had a duration between 60 and 90 minutes and it was always performed on an artificial field $(100 \times 51 \mathrm{~m})$. Training sessions were generally composed by three consecutive parts: i) warm up, ii) a central part aimed by physical or technical/tactical components, and iii) training match activity played in small dimensions and with reduced number of players (e.g., 7v7)

Ethical approval for the study was obtained from the Ethical Advisory Committee of the university of Rome "Sapienza" (Rome, Italy), while before its commencement players and parents/guardians were provided with a written and verbal summary outlining the purpose and procedures involved, and then invited to sign a written consent form. Once completed the "entire-season" data collection, the statistical analysis was provided only for players that fulfilled the following criteria of inclusion: 1) having complete taken part to all tests sessions; 2) being in a no-injury status during each test session; 3) goalkeepers were not considered for the study. Thus, seventeen players were not included for the statistical analysis.

\section{Procedure}

The study included a field-test battery composed by six skill tests validated by Malina et al. (2005): i) Touch of the ball with the body (TWB); ii) Touch of the ball with the head (TWH); iii) Passing (PA); iv) Shooting (SH); v) Dribbling with pass (DWP); and vi) Dribbling (DRI), and three fitness tests: i) countermovement jump (CM) with the hand on the hip (CMJHH); ii) countermovement jump with free arms (CMJFH); and iii) $15 \mathrm{~m}$ linear speed test (SPE).

Data were collected during the entire-season along six experimental sessions, which were all administrated on an artificial indoor turf surface and scheduled always during the second weekly training unit (on Thursday) at the same hour $(3: 00 \mathrm{pm})$ to avoid the influence of circadian rhythms (Reilly et al., 2000). Each session began with 25-min of standardized warmup composed by physical and technical exercises without static stretching, then two trials for each test were submitted and the best trial was considered for the statistical analysis. Participants were instructed to consume their normal pre-training meal (avoiding caffeinated drinks) and refrain from strenuous exercise for at least $48 \mathrm{~h}$ prior to the experimental sessions.

\section{Statistical analysis}

Data was collected using a spread sheet (Microsoft Office Excel 2011, Microsoft Corporation, Redmond, WA, USA) and subsequently analyzed with statistical software SPSS package (ver. 21.0, Institute Inch., Cary, NC). Data were expressed as mean \pm SD and the criterion of significance was set at $p<0.05$. All data set were assessed for the assumption of normality using the Kolmogorov-Smirnov test for normality of distribution statistic. Moreover, Friedman test was used to evaluate the anthropometrical, technical and physical differences of each player trough the field-battery test. Where significant differences were observed, a follow-up Wilcoxon signed ranks test was used to compare individual pairs of performance in different times and calculated the phi effect size considering $0.1,0.3$, and 0.5 as small, medium and large effects, respectively (Huck, 2000). Afterwards, Pearson's correlation was adopted to assess the following parameters: 1) relationships between the variation of each skill test (i.e. TWB, TWH, PA, SH, DWP, DRI) and time set by coaches to focused on technical and tactical abilities; 2) relationship between physical capacities variation (i.e. CMJ, CMJFA, SPE) with time focused on the development this abilities. 
Francioni, F. M.; Figueredo, A. J.; Lupo, C.; Terribili, M.; Condello, G., \& Tessitore, A. (2018). Intra-seasonal variation of anthropometrical, conditional, and technical tests in U14 soccer players. RICYDE. Revista internacional de ciencias del deporte, 53(14), 219-232. https://doi.org/10.5232/ricyde2018.05303

\section{Results}

No significant difference was found for players' age groups (13 yrs and yrs old), thus, data were pooled and further analysis was allowed. Values for anthropometric measurements (i.e. chronological age, body mass and stature) are showed in the upper part (part "a") of table 1 . In the lower part (part "b") mean $(\mathrm{M} \pm S D)$ and range (min - max) of values regarding the training diary (i.e. number of training scheduled, minutes of appearances for the amount of training, minutes of training spent to develop technical and tactical abilities, and conditional capacities) were provided.

The number of training sessions were planned by the clubs, while their durations were determined by the coaches (Table 1). Moreover, the attendance to training activity was collected along the five consecutive periods and represented in the same table with the range values. 
Francioni, F. M.; Figueredo, A. J.; Lupo, C.; Terribili, M.; Condello, G., \& Tessitore, A. (2018). Intra-seasonal variation of anthropometrical, conditional, and technical tests in U14 soccer players. RICYDE. Revista internacional de ciencias del deporte, 53(14), 219-232. https://doi.org/10.5232/ricyde2018.05303

Table 1. Descriptive statistics for anthropometrical output and training diary values observed during the intra-seasons periods.

\begin{tabular}{|c|c|c|c|c|c|c|}
\hline & $\begin{array}{c}\text { T0 } \\
\text { (August) }\end{array}$ & $\begin{array}{c}\text { T1 } \\
\text { (October) }\end{array}$ & $\begin{array}{c}\mathrm{T} 2 \\
\text { (December) }\end{array}$ & $\begin{array}{c}\text { T3 } \\
\text { (February) }\end{array}$ & $\begin{array}{c}\text { T4 } \\
\text { (April) }\end{array}$ & $\begin{array}{c}\text { T5 } \\
\text { (June) }\end{array}$ \\
\hline \multicolumn{7}{|l|}{ a) Anthropometric } \\
\hline Chronological Age (years) & $13.6 \pm 0.6$ & $13.8 \pm 0.6$ & $14 \pm 0.6$ & $14.1 \pm 0.6$ & $14.3 \pm 0.6$ & $14.5 \pm 0.6$ \\
\hline Body mass (Kg) & $53.6 \pm 11.4$ & $54 \pm 11.5$ & $54.5 \pm 11.6$ & $55.6 \pm 11.3$ & $56.8 \pm 10.8$ & $57.8 \pm 10.6$ \\
\hline Stature $(\mathrm{Cm})$ & $162.7 \pm 8.7$ & $162.9 \pm 8.7$ & $163.2 \pm 8.6$ & $163.5 \pm 8.5$ & $164.5 \pm 8.1$ & $166.2 \pm 8.3$ \\
\hline \multicolumn{7}{|l|}{ b) Training diary } \\
\hline N. Training units (n.) & & 24 & 18 & 23 & 15 & 11 \\
\hline \multirow[t]{2}{*}{ Total Appearances (min) } & & $2438 \pm 610$ & $1922 \pm 667$ & $2696 \pm 534$ & $1948 \pm 537$ & $1012 \pm 316$ \\
\hline & & $(1557-4052)$ & $(246-3165)$ & $(1748-3535)$ & $(263-2566)$ & $(398-1481)$ \\
\hline \multirow[t]{2}{*}{ Technical and tactical (min) } & & $1697 \pm 369$ & $703 \pm 244$ & $1000 \pm 195$ & $723 \pm 199$ & $480 \pm 152$ \\
\hline & & $(756-2076)$ & $(89-1159)$ & $(641-1304)$ & $(95-949)$ & $(186-704)$ \\
\hline \multirow[t]{2}{*}{ Conditional (min) } & & $292 \pm 76$ & $516 \pm 179$ & $695 \pm 145$ & $503 \pm 139$ & $52 \pm 17$ \\
\hline & & $(45-350)$ & $(68-847)$ & $(434-927)$ & $(73-668)$ & $(21-73)$ \\
\hline
\end{tabular}


Francioni, F. M.; Figueredo, A. J.; Lupo, C.; Terribili, M.; Condello, G., \& Tessitore, A. (2018). Intra-seasonal variation of anthropometrical, conditional, and technical tests in U14 soccer players. RICYDE. Revista internacional de ciencias del deporte, 53(14), 219-232. https://doi.org/10.5232/ricyde2018.05303

Table 2. Coefficient of Variation in percentage (CV), Means \pm standard deviations, differences (i.e., $p \leq 0.05)$ and effect sizes (ES) between intra-seasons periods of each technical and physical test (i.e., touch with the body, TWB; touch with the head, TWH; pass accuracy, PASS; shooting, SH; dribbling with pass, DWP; dribbling, DRI; speed, SPE; countermovement jump with the hand on the hip, CMJHH; countermovement jump with free arms, CMJFH).

\begin{tabular}{|c|c|c|c|c|c|c|c|}
\hline Field tests & CV \% & $\begin{array}{c}\text { T0 } \\
\text { (August) }\end{array}$ & $\begin{array}{c}\text { T1 } \\
\text { (October) } \\
\end{array}$ & $\begin{array}{c}\text { T2 } \\
\text { (December) } \\
\end{array}$ & $\begin{array}{c}\text { T3 } \\
\text { (February) } \\
\end{array}$ & $\begin{array}{c}\text { T4 } \\
\text { (April) }\end{array}$ & $\begin{array}{c}\text { T5 } \\
\text { (June) }\end{array}$ \\
\hline TWB (n) & 106.2 & $21.1 \pm 20.9$ & $27.2 \pm 20.7$ & $23.7 \pm 21.5$ & $\begin{array}{c}29.6 \pm 18.4 \\
*(0.2), ¥(0.1)\end{array}$ & $\begin{array}{c}47.8 \pm 41.3 \\
*(0.4), \#(0.3), ¥(0.3), \uparrow(0.3)\end{array}$ & $\begin{array}{c}47.8 \pm 50.3 \\
*(0.3), \#(0.3), ¥(0.3), \uparrow(0.2), \dagger(0.1)\end{array}$ \\
\hline \multirow[t]{2}{*}{ TWH (n) } & 69.4 & $4.7 \pm 3.5$ & $5.0 \pm 2.8$ & $4.8 \pm 2.8$ & $4.9 \pm 3.1$ & $6.9 \pm 5.4$ & $5.6 \pm 4.2$ \\
\hline & & & & & & $*(0.2), \#(0.2), ¥(0.2), \uparrow(0.2)$ & \\
\hline \multirow[t]{2}{*}{ PASS (point) } & 66.4 & $1.3 \pm 1.2$ & $2.1 \pm 1.7$ & $2.3 \pm 1.3$ & $2.5 \pm 1.3$ & $2.4 \pm 1.3$ & $3.5 \pm 1.6$ \\
\hline & & & $*(0.3)$ & $*(0.4)$ & $*(0.4)$ & $*(0.4)$ & $*(0.6), \#(0.4), ¥(0.4), \uparrow(0.3), \dagger(0.4)$ \\
\hline \multirow[t]{2}{*}{ SH (point) } & 42.6 & $8.0 \pm 4.0$ & $10.4 \pm 4.3$ & $12.0 \pm 4.1$ & $11.5 \pm 4$ & $14.5 \pm 4.5$ & $12.5 \pm 5.4$ \\
\hline & & & $*(0.3)$ & $*(0.5), \#(0.2)$ & $*(0.4)$ & $*(0.6), \#(0.4), ¥(0.3), \uparrow(0.3)$ & $*(0.4), ¥(0.1)$ \\
\hline \multirow[t]{2}{*}{ DWP (sec) } & 17.2 & $11.9 \pm 2.2$ & $10.7 \pm 2.0$ & $10.4 \pm 1.6$ & $9.8 \pm 1.3$ & $9.8 \pm 1.2$ & $10.0 \pm 1.0$ \\
\hline & & & $*(0.2)$ & $*(0.4)$ & $*(0.5), \#(0.3)$ & $*(0.5), \#(0.3), ¥(0.2)$ & $*(0.5), \#(0.2), ¥(0.1)$ \\
\hline \multirow[t]{2}{*}{ DRI (sec) } & 13.8 & $15.0 \pm 2.5$ & $13.7 \pm 2.1$ & $13.1 \pm 1.7$ & $14.9 \pm 1.8$ & $15.1 \pm 1.8$ & $15.2 \pm 1.7$ \\
\hline & & & $*(0.3)$ & $*(0.4), \#(0.2)$ & $\#(0.3), ¥(0.4)$ & $\#(0.3), ¥(0.5)$ & $\#(0.4), ¥(0.5)$ \\
\hline \multirow[t]{2}{*}{ SPE (sec) } & 7.1 & $2.9 \pm 0.2$ & $2.9 \pm 0.2$ & $2.9 \pm 0.3$ & $2.9 \pm 0.2$ & $2.9 \pm 0.2$ & $2.8 \pm 0.2$ \\
\hline & & & & $*(0.1)$ & $*(0.1)$ & $*(0.1)$ & $*(0.2), \#(0.2), ¥(0.1), \uparrow(0.1), \dagger(0.1)$ \\
\hline \multirow[t]{2}{*}{ CMJHH $(\mathrm{Cm})$} & 21.1 & $21.8 \pm 4$ & $23.6 \pm 4.3$ & $25.6 \pm 4.6$ & $24.6 \pm 4.4$ & $25.4 \pm 4.8$ & $25.5 \pm 4.6$ \\
\hline & & & $*(0.2)$ & $*(0.4), \#(0.2)$ & $*(0.3)$ & $*(0.4), \#(0.2)$ & $*(0.4), \#(0.2)$ \\
\hline \multirow[t]{2}{*}{ CMJFH (Cm) } & 20.9 & $26.4 \pm 5.4$ & $27.6 \pm 4.6$ & $29.5 \pm 5.8$ & $29.8 \pm 6.1$ & $30.1 \pm 5.9$ & $31.5 \pm 5.6$ \\
\hline & & & $*(0.1)$ & $*(0.3), \#(0.2)$ & $*(0.3), \#(0.2)$ & $*(0.3), \#(0.2), ¥(0.1)$ & $*(0.4), \#(0.4), ¥(0.2)$ \\
\hline
\end{tabular}

Differences from T0, *; Differences from T1, \#; Differences from T2, ¥; Differences from T3, ;; Differences from T4, $\dagger$

In Table 2 are reported all data $(\mathrm{M} \pm \mathrm{SD})$ regarding the technical and the physical capacities during the football season with the significant differences with the effects size. Four technical (i.e., TWB, PASS, SH, DWP) and three physical tests (SPE, CMJHH and CMJFH) showed significant differences (p < 0.001) between T0 and T5, contrarily to TWH and DRI where no significant differences were observed. According to Table 3, variations of technical and physical capacities were related to the amount of training spent to develop the same capacities. 
Francioni, F. M.; Figueredo, A. J.; Lupo, C.; Terribili, M.; Condello, G., \& Tessitore, A. (2018). Intra-seasonal variation of anthropometrical, conditional, and technical tests in U14 soccer players. RICYDE. Revista internacional de ciencias del deporte, 53(14), 219-232. https://doi.org/10.5232/ricyde2018.05303

Table 3. Significant relationship between time of training, technical and physical variations along the five period of test (T1).

\begin{tabular}{|c|c|c|c|c|c|}
\hline Field tests & $\Delta \mathrm{T} 0-\mathrm{T} 1$ & $\Delta \mathrm{T} 1-\mathrm{T} 2$ & $\Delta T \mathrm{~T} 2-\mathrm{T} 3$ & $\Delta \mathrm{T} 3-\mathrm{T} 4$ & $\Delta \mathrm{T} 4-\mathrm{T} 5$ \\
\hline TWB (n) & $6 \pm 21$ & $-3 \pm 22$ & $6 \pm 22$ & $18 \pm 31$ & $0 \pm 33$ \\
\hline TWH (n) & $0 \pm 3$ & $0 \pm 3$ & $0 \pm 3$ & $2 \pm 3$ & $-1 \pm 5$ \\
\hline PASS (point) & $1 \pm 2$ & $0 \pm 2$ & $0 \pm 1$ & $0 \pm 2$ & $1 \pm 2$ \\
\hline SH (point) & $2 \pm 4$ & $2 \pm 4$ & $-1 \pm 5$ & $3 \pm 4$ & $-2 \pm 6$ \\
\hline DWP (sec) & $1.3 \pm 1.0^{*}$ & $0.2 \pm 1.9$ & $0.6 \pm 1.6$ & $0.0 \pm 1.1$ & $0.2 \pm 1.1$ \\
\hline DRI (sec) & $1.2 \pm 1.6$ & $0.7 \pm 1.6$ & $-1.8 \pm 1.9$ & $-0.2 \pm 1.5$ & $-0.2 \pm 2.0$ \\
\hline SPE (sec) & $0.0 \pm 0.1$ & $0.0 \pm 0.2$ & $0.0 \pm 0.2$ & $0.0 \pm 0.1$ & $0.0 \pm 0.1$ \\
\hline $\begin{array}{l}\text { CMJ HH } \\
(\mathrm{Cm})\end{array}$ & $1.8 \pm 1.6$ & $1.9 \pm 1.7$ & $-1.0 \pm 3.0$ & $0.8 \pm 2.2$ & $0.1 \pm 2.3$ \\
\hline $\begin{array}{l}\text { CMJ FH } \\
(\mathrm{Cm})\end{array}$ & $1.2 \pm 2.1$ & $1.9 \pm 3.1$ & $0.3 \pm 3.3$ & $0.3 \pm 2.1$ & $1.3 \pm 2.5$ \\
\hline
\end{tabular}

Values represent mean and standard deviation $(\mathrm{M} \pm \mathrm{SD})$.

$*_{\mathrm{r}}=-0.3 ; p<0.05$.

\section{Discussion}

The novelty of this study was to assess the variations of results of anthropometrical, technical and physical tests in young soccer players by means of an annual longitudinal approach based on six tests sessions taken during the same season, as well as to analyze the relationship between each variation of tests' results, given by the difference between two successive test sessions (e.g., between $\mathrm{T} 1$ and $\mathrm{T} 0$ ) and the amount of training time spent during the five corresponding periods (e.g., $\Delta \mathrm{T} 1 / \mathrm{T} 0$ vs P1). It was assumed that players should have shown a constant improvement of all variables with the lowest and the best values at the beginning end at the end of the season, respectively.

The major findings of this study showed significant variations of technical and conditional results along the six tests sessions (i.e., $\Delta \mathrm{T} 1 / \mathrm{T} 0 ; \Delta \mathrm{T} 2 / \mathrm{T} 1 ; \Delta \mathrm{T} 3 / \mathrm{T} 2 ; \Delta \mathrm{T} 4 / \mathrm{T} 3 ; \Delta \mathrm{T} 5 / \mathrm{T} 4$ ), although they were not related to the amount of time spent in training activities during each periods (i.e., P1; P2; P3; P4; P5). In fact, the results clearly indicated a non-linear trend of increases along the season in relation to the amount of training sessions performed. Thus, it can be rejected the hypothesis of a linear relationship between the amount of time spent in training and an eventual increment of performance registered during tests (Francioni et al., 2016). On the other hand, the anthropometrical results consistently increased during each observed period of the season, confirming the results of previous studies involving sub-elite football players aged 13-14 (Figueiredo, Goncalves, Coelho-e-Silva and Malina, 2009b; Valente-dos-Santos, Coelho-eSilva, Martins, Figuiredo, Cyrinho, Sherar, Vaeyens, Huijgen, Elferink-Gemser and Malina, 2012; Vaeyens et al., 2006). 
Francioni, F. M.; Figueredo, A. J.; Lupo, C.; Terribili, M.; Condello, G., \& Tessitore, A. (2018). Intra-seasonal variation of anthropometrical, conditional, and technical tests in U14 soccer players. RICYDE. Revista internacional de ciencias del deporte, 53(14), 219-232. https://doi.org/10.5232/ricyde2018.05303

In general, when assessing youth athletes should be considered the characteristics and features of the tasks that constitute the field-test battery. Indeed, in soccer, the individual outcomes of performance are affected by the players' proficiency of skills (Russell and Kingsley, 2011). On the other hand, the dichotomy between physical and skill components may be shown or not by the type of assessment adopted (Lidor et al., 2009). For this reason, for projects related to both research and field evaluations, soccer skills have been often isolated and mainly categorized in tests assessing ball control and ball accuracy in particular in these age-group categories where coaches are focused on the develop of technical and elementary tactical skills as demonstrated by previous studies (Coutinho, Gonçalves, Figueira, Abade, Marcelino, and Sampaio, 2015). For instance, despite the ecological validity of the test ball-juggling is still questionable compared to more match-specific actions such as dribbling due to an infrequent use of this skill (Ali, 2011; Russell and Kingsley, 2011), in this study we referred to the reliability shown by the work of Figueiredo, Coelho e Silva and Malina (2011) which reported a reliable ball juggling task (coefficient of reliability: 0.77 ) with athletes of the same age-category (13- to 14year). Hence the ability to touch the ball with the body has been assessed by TWB and TWH tests and our players showed a lower mean score compared to those obtained by Portuguese youth elite level players (Malina et al., 2005), but proximate to the TWB results for the same sub-level age-category (Rosch et al., 2000). Furthermore, considering the six test sessions submitted in this study, differences $(\mathrm{p}<0.05)$ were found between the initial $(\mathrm{T} 0)$ and last sessions of the season (T3 and T5). Based on previous experience, the above mentioned reliability of these tests has not changed the idea of the authors regarding the TWH and TWB, which may be affected by several factors (e.g., attention, motivation, technical level) that can mislead a real and contextualized evaluation.

The winning and losing of possession during a game is also determined by the accuracy of players' ability to execute technical skills (Huijgen, Elferink-Gemser, Ali and Visscher, 2013). In this respect, in this study the assessment of the players' passing ability has been evaluated with the PASS test where players start it in a static position, while in the Loughborough test protocol (to mention a different approach) they were assessed in a dynamic situation (Ali, Williams, Hulse, Strudwick, Reddin, Howarth and Eldred, 2007). The results of this study showed a general improvement of values across the season, as confirmed by the rising effects from 0.3 (T2) to 0.6 (T5). In particular, data collected at mid-season (T3) were similar to those collected at the correspondent annual phase of Portuguese youth elite players (Malina et al., 2005), although the lack of data at the end of the season has not permitted a complete comparison with the literature, underlining the necessity of repeated measurements in order to increase in-seasonal assessments.

Regarding the shooting ability ( $\mathrm{SH})$, the results of this study showed significant differences for all the test sessions during the season compared to the beginning (T0), with effects from small to large observed from T3 to T5. However, as well for PASS test, also SH test could be considered with not high specificity due to the static situation adopted to start its execution that is not actually reproducing the specific movements performed during a match.

Dribbling is consider a valuable skill in soccer players, since it can be helpful, for instance, to advance deeper into an opponent's territory while maintaining possession of the ball. In this study such skill was assessed by means of DRI and DWP tests which showed differences during all time periods of assessment, with larger effects for DRI respect to DWP in all test sessions. Generally, dribbling tests are considered as a good indicator of the football performance with significant differences by age- and level-category of players (Reilly et al., 2000). Accordingly, our data were similar to those provided for DWP test submitted to youth sub-elite level players (Vaeyens et al., 2006), while were slightly lower compared with Portuguese youth elite players 
Francioni, F. M.; Figueredo, A. J.; Lupo, C.; Terribili, M.; Condello, G., \& Tessitore, A. (2018). Intra-seasonal variation of anthropometrical, conditional, and technical tests in U14 soccer players. RICYDE. Revista internacional de ciencias del deporte, 53(14), 219-232. https://doi.org/10.5232/ricyde2018.05303

(Figueiredo et al., 2009a; Malina et al., 2005). This could be explained by the fact that this test should be considered more as a "run with the ball test" rather than a "dribbling ability test", due to the small dribbling-demand (turning with the ball) required.

In general, the U-14 category is considered to be crucial for the selection of players of different competitive level due to the differences in physical and physiological attributes (Le Gall et al., 2010). Previous studies with U-15 and U-17 soccer age-categories have demonstrated how physical field-test batteries were not always able to distinguish the abilities of future professional, national, and international players (Le Gall et al., 2010; Vaeyens et al., 2006, Rosch et al., 2000). The importance to perform maximal or sub-maximal sprints on short distances has been widely argued in literature and considered as one of the successful key in youth football talent identification (Vaeyens et al., 2006). Specifically, in this study was submitted a 15-m sprint test, which is not frequently adopted in literature for this age-category, except the work of Reilly et al. (2000) and Francioni et al. (2016). Nevertheless, our results are similar to those provided in a cross sectional study focused on the assessment of 15-m straightsprint in youth Italian rugby players (Condello, Minganti, Lupo, Benvenuti, Pacini and Tessitore, 2013). The results of our study showed significant improvements in the second half of the season, with more effects registered for the last session (T5), which is when the training loads were lower respect to the first part of the year. A similar trend was also observed for $\mathrm{CMJHH}$ and CMJFA parameters, where a significant difference occurred during the last tests session (T5) compared to the one after the first period of training (T1). This fact denotes that players improved their performances at the end of the season when the volume of loads spent for physical training was diminishing (percentage of distribution at T5: 90\% technical and 10\% physical drills). Moreover, the difference between CMJHH and CMJFA improved along the season, which could be explained by an improvement of the players' coordinative abilities that represents a relevant characteristic to success in youth football (Tessitore, Perroni, Cortis, Meeusen, Lupo and Capranica, 2011). Furthermore, similar CMJFA results obtained in previous studies for athletes of the same level were found (Malina, Ribeiro, Aroso and Cumming, 2007), even if have also been shown different values from youth players with a professional perspective (Carling et al, 2009). Although a strong correlation between the maximum muscle strength and the sprinting ability has been previously showed by the literature (Peñailillo, Espíldora, Jannas-Vela, Mujika, and Zbinden-Foncea, 2016), the significant difference observed by our study for SPE occurred prevalently when they were compared with one of the sixth assessments. This could be provoked by the fact that field based measures are sometime unable to identify small meaningful changes in the force generated by muscle (Gibson, Brownstein, Ball, and Twist, 2017).

In general, the short periods of data collection adopted in most of previous studies with young players of the same age-category has complicated the comparison of these results. Indeed, an experimental design that relies on only two sessions cannot be able to identify all seasonal variations of data (Francioni et al., 2016), neglecting the in-seasonal dynamic development of training. In fact, this study showed that not all the capacities and skills show a similar and regular variation of results (aimed to increase the level of proficiency) during the season. For this reason, assessments based on repeated measurements during the season could help the talent identification process in order to collect more deep information on individual response to training adaptation.

The analysis of the log in relation to the five training periods of our study showed that players performed a higher amount (total minutes) of exercise during the first and third period, due to the higher frequency of weekly training units scheduled. In fact, these weeks corresponded to the end of August/beginning of September (P1) and Christmas break (P2), when players were 
Francioni, F. M.; Figueredo, A. J.; Lupo, C.; Terribili, M.; Condello, G., \& Tessitore, A. (2018). Intra-seasonal variation of anthropometrical, conditional, and technical tests in U14 soccer players. RICYDE. Revista internacional de ciencias del deporte, 53(14), 219-232. https://doi.org/10.5232/ricyde2018.05303

free from the school attendance and the clubs could plan more training sessions. Otherwise, the lowest number of training units was registered during the last period of the season (P5), which was particularly determined after the last official match of the championship by the high number of matches played in post-championship tournaments. Furthermore, the total amount of training-time spent to develop technical and tactical skill was consistently higher compared to the conditional one in each of the five observed periods, as suggested by the literature to improve the specific soccer skills (Malina et al., 2007; Rosch et al., 2000). However, if we consider the distribution of the percentage of time spent in physical (conditional) and technical/tactical training the former was higher during the first part of the season and the latter was markedly higher during the last one, when the time spent in competitions was also increased.

\section{Conclusions}

In conclusion, the findings of this study can be summarised with the following considerations. First, although all tests used in this study have been validated in the literature (Malina et al., 2005), it can be confirmed, as suggested by other authors, that these tests may have a low ecological validity in respect to the skills required during a soccer match (Ali, 2011). Second, as maturity status was not assessed it is unknown whether player biological age was similar or varied. It could be that more mature players had greater neuromuscular control which may have affected test performance (Meylan et al., 2010; Musch and Grondin, 2001; Oliver and Smith, 2010). Indeed, athlete development cannot be considered as linear, but rather as an unstable and uncertain process, based on the growth and maturity status of the player (Figueiredo et al., 2011). Thus, this work underlined the importance of longitudinal studies investigating the talent identification process, in order to quantify and explain the fluctuations in results (Francioni et al., 2016). In addition, when research is restricted to a cross sectional design, information regarding the current training plan at the time of testing should be provided to permit the comprehension and the comparison of results. Moreover, the present findings confirm the importance of multi-dimensional and longitudinal assessment in youth football talent identification and reinforce the preference to focus on technical over physical capacities (Figueiredo et al, 2009b; Francioni et al., 2016). Finally, club staff should evaluate youth players towards the end of the championship, comparing results from the start of the season to observe in-season adaptations, focusing particularly on technical skills (i.e., PASS, DWP and DRI). In fact, decisions regarding talent identification and development should be done with a perspective view, considering the real contemporary skill's level of players and the development along the last season (Francioni et al., 2016). The development of such process needs to be regulated by the management of the training load in order to optimize physical and technical skills, reducing the risk of injury that may occur in the youth players (Gabbett, 2016).

\section{References}

Abbott, A., and Collins, D. (2004). Eliminating the dichotomy between theory and practice in talent identification and development, considering the role of psychology. Journal of Sports Sciences, 22(5), 395-408. https://doi.org/10.1080/02640410410001675324

Ali, A.; Williams, C.; Hulse, M.; Strudwick, A.; Reddin, J., Howarth, L., Eldred, J.; Hirst, M., and McGregor, S. (2007). Reliability and validity of two tests of soccer skill. Journal of Sports Sciences, 25(13), 1461-1470. https://doi.org/10.1080/02640410601150470 
Francioni, F. M.; Figueredo, A. J.; Lupo, C.; Terribili, M.; Condello, G., \& Tessitore, A. (2018). Intra-seasonal variation of anthropometrical, conditional, and technical tests in U14 soccer players. RICYDE. Revista internacional de ciencias del deporte, 53(14), 219-232. https://doi.org/10.5232/ricyde2018.05303

Ali, A. (2011). Measuring soccer skill performance, a review. Scandinavian Journal of Medicine in Science of Sports, 21(2), 170-183. https://doi.org/10.1111/j.1600-0838.2010.01256.x

Carling, C.; Le Gall, F.; Reilly, T., and Williams, A.M. (2009). Do anthropometric and fitness characteristics vary according to birth date distribution in elite youth academy soccer players? Scandinavian Journal of Medicine in Science of Sports, 19(1), 3-9. https://doi.org/10.1111/j.1600-0838.2008.00867.x

Condello, G.; Minganti, C.; Lupo, C.; Benvenuti, C.; Pacini D., and Tessitore, A. (2013). Evaluation of Change-of-Direction Movements in Young Rugby Players. International Journal of Sports Physiology and Performance, 8(1), 52-55.

https://doi.org/10.1123/ijspp.8.1.52

Coutinho, D., Gonçalves, B., Figueira, B., Abade, E., Marcelino, R., and Sampaio, J. (2015). Typical weekly workload of under 15 , under 17 , and under 19 elite Portuguese football players. Journal of Sports Sciences, 33(12), 1229-1237.

https://doi.org/10.1080/02640414.2015.1022575

Elferink-Gemser, M.T.; Visscher, C.; Lemmink, K.A.; and Mulder, T. (2007). Multidimensional performance characteristics and standard of performance in talented youth field hockey players: A longitudinal study. Journal of Sports Science, 25(4), 481489.

https://doi.org/10.1080/02640410600719945

Figueiredo, A.J.; Coelho E Silva, M.J.; and Malina, R.M. (2011). Predictors of functional capacity and skill in youth soccer players. Scandinavian Journal of Medicine in Science of Sports, 21(3), 446-54.

https://doi.org/10.1111/j.1600-0838.2009.01056.x

Figueiredo, A.J.; Goncalves, C.; Coelho-e-Silva, M.J.; and Malina, R. (2009b). Characteristics of youth soccer players who drop out, persist or move up. Journal of Sports Science, 27(9), 883-891.

https://doi.org/10.1080/02640410902946469

Figueiredo, A.J.; Goncalves, C.; Coelho-e-Silva, M.J.; and Malina, R. (2009a). Youth soccer players, 11-14 years, Maturity, size, function, skill and goal orientation. Annals of Human Biology, 36(1), 60-73.

https://doi.org/10.1080/03014460802570584

Francioni, F.M.; Figueiredo, A.J.; Terribili, M., and Tessitore, A. (2016). Analysis of the intraseasonal stability of field test performances in young academy soccer players. Journal of Sports Science, 34(10), 966-972.

https://doi.org/10.1080/02640414.2015.1082612

Gabbett, T. J. (2016). The training-injury prevention paradox: should athletes be training smarter and harder? British Journal of Sports Medicine, 50, 273-280.

https://doi.org/10.1136/bjsports-2015-095788

Gibson, N., Brownstein, C., Ball, D., and Twist, C. (2017). Physiological, perceptual and performance responses associated with self-selected versus standardized recovery periods during a repeated sprint protocol in elite youth football players: A preliminary study. Pediatric exercise science, 29(2), 186-193.

https://doi.org/10.1123/pes.2016-0130

Gullich, A.; and Emrich, E. (2006). Evaluation of the support of young athletes in the elite sport system. European Journal of Sport Society, 3(2), 85-108. https://doi.org/10.1080/16138171.2006.11687783

Helsen, W.F.; Van Winckel, J.; and Williams, A.M. (2005). The relative age effect in youth soccer across Europe. Journal of Sports Science, 23(6), 629-636.

https://doi.org/10.1080/02640410400021310 
Francioni, F. M.; Figueredo, A. J.; Lupo, C.; Terribili, M.; Condello, G., \& Tessitore, A. (2018). Intra-seasonal variation of anthropometrical, conditional, and technical tests in U14 soccer players. RICYDE. Revista internacional de ciencias del deporte, 53(14), 219-232. https://doi.org/10.5232/ricyde2018.05303

Holt, N.L.; Mitchell. T.; and Button, C. (2006). Talent development in English professional soccer. International Journal of Sport Psychology, 37(2/3), 77-98.

Huck, S.W. (2000). Reading Statistics and Research, 3rd ed., Addition, Wesly Longman, Compaign.

Huijgen, B.C.H; Elferink-Gemser, M.T.; Ali, A.; and Visscher, C. (2013). Soccer Skill Development in Talented Players. International Journal of Sports Medicine, 34(8), 720726.

https://doi.org/10.1055/s-0032-1323781

Le Gall, F.; Carling, C.; Williams M.; and Reilly, T. (2010). Anthropometric and fitness characteristics of international, professional and amateur male graduate soccer players from an elite youth academy. Journal of Sport Science in Medicine of Sport, 13(1), 9095.

https://doi.org/10.1016/j.jsams.2008.07.004

Lidor, R.; Còtè, J.; and Hackfort, D. (2009) ISSP position stand, to test or not to test? The use of physical skill tests in talent detection and in early phases of sport development. International Journal of Sport Exercise and Physiology, 7(2), 131-146. https://doi.org/10.1080/1612197X.2009.9671896

MacNamara, A.; Buttan, A.; and Collins, D. (2010a). The role of psychological characteristics in facilitating the pathway to elite performance. Part 1, Identifying mental skills and behaviours. Sport Psychology, 24(1), 52-73.

https://doi.org/10.1123/tsp.24.1.52

MacNamara, A.; Buttan, A.; and Collins, D. (2010b). The role of psychological characteristics in facilitating the pathway to elite performance. Part 2, Examining environmental and stage related differences in skills and behaviors. Sport Psychology, 24(1), 74-96. https://doi.org/10.1123/tsp.24.1.74

MacNamara, A.; and Collins, D. (2011). Comment on "Talent identification and promotion programmes of Olympic athletes". Journal of Sports Science, 29(12), 1353-1356. https://doi.org/10.1080/02640414.2011.568510

Malina, R.M.; Cumming, S.P.; Kontos, A.P.; Eisenmann, J.C.; Ribeiro, B.; and Aroso, J. (2005). Maturity-associated variation in sport-specific skills of youth soccer players aged 13-15 years. Journal of Sports Science, 23(5), 515-522.

https://doi.org/10.1080/02640410410001729928

Malina, R.M.; Ribeiro, B.; Aroso, J.; and Cumming, S.P. (2007). Characteristics of youth soccer players aged 13-15 years classified by skill level. British Journal of Sports Medicine, 41(5), 290-295.

https://doi.org/10.1136/bjsm.2006.031294

Mendez-Villanueva, A.; Buchheit, M.; Kuitunen, S.; Douglas, A.; Peltola, E.; and Bourdon, P. (2011). Age-related differences in acceleration, maximum running speed, and repeated- sprint performance in young soccer players. Journal of Sports Science, 29(5), 477-484. https://doi.org/10.1080/02640414.2010.536248

Meylan, C.; Cronin, J.; Oliver, J.; and Hughes, M. (2010). Reviews, Talent Identification in Soccer, The Role of Maturity Status on Physical, Physiological and Technical Characteristics. International Journal of Sports Science and Coaching, 5(4), 571-592. https://doi.org/10.1260/1747-9541.5.4.571

Miranda, R.E.E.P.C.; Antunes, H.K.M.; Pauli, J.R.; Puggina, E.F.; and Da Silva, A.S.R. (2013). Effects of 10-week soccer training program on anthropometric, psychological, technical skills and specific performance parameters in youth soccer players. Science Sports, 28(2), 81-87.

https://doi.org/10.1016/j.scispo.2012.02.005 
Francioni, F. M.; Figueredo, A. J.; Lupo, C.; Terribili, M.; Condello, G., \& Tessitore, A. (2018). Intra-seasonal variation of anthropometrical, conditional, and technical tests in U14 soccer players. RICYDE. Revista internacional de ciencias del deporte, 53(14), 219-232. https://doi.org/10.5232/ricyde2018.05303

Musch, J.; and Grondin S. (2001). Unequal competition as an impediment to personal development, a review of the relative age effect in sport. Dev Rev, 21(2), 147-167. https://doi.org/10.1006/drev.2000.0516

Oliver, J.L.; and Smith PM. (2010). Neural control of leg stiffness during hopping in boys and man. Journal of Electromyography and Kinesiology, 20(5), 973-979. https://doi.org/10.1016/j.jelekin.2010.03.011

Peñailillo, L., Espíldora, F., Jannas-Vela, S., Mujika, I., and Zbinden-Foncea, H. (2016). Muscle strength and speed performance in youth soccer players. Journal of human kinetics, 50(1), 203-210.

Reilly, T.; Williams, A.M; Nevill, A.; and Franks A. (2000). A multidisciplinary approach to talent identification in soccer. Journal of Sport Science, 18(9), 695-702. https://doi.org/10.1080/02640410050120078

Rosch, D.; Hodgson, R.; Peterson, L.; Graf-Baumann, T.; Junge, A.; Chomiak, J.; and Dvorak, J. (2000). Assessment and Evaluation of Football Performance. Amererican Journal of Sports Medicine, 28(suppl 5), S29-39. https://doi.org/10.1177/28.suppl_5.s-29

Russell, M.; and Kingsley M. (2011). Influence of exercise on skill proficiency in soccer. Sports Medicine, 41(7), 523-539. https://doi.org/10.2165/11589130-000000000-00000

Tessitore, A.; Perroni, F.; Cortis, C.; Meeusen, R.; Lupo, C.; and Capranica, L. (2011). Coordination of soccer players during preseason training. Journal Strength and Conditioning Research, 25(11), 3059-3069. https://doi.org/10.1519/JSC.0b013e318212e3e3

Unnithan, V.; White, J.; Georgiou, A.; Iga, J.; and Drust, B. (2012). Talent identification in youth soccer. Journal of Sports Science, 30(15), 1719-1726. https://doi.org/10.1080/02640414.2012.731515

Vaeyens, R.; Malina, R.M.; Janssens, M.; Van Renterghem, B.; Bourgois, J.; Vrijens, J.; and Philippaerts, R.M. (2006). A multidisciplinary selection model for youth soccer, the Ghent Youth Soccer Project. British Journal of Sports Medicine, 40(11), 928-934. https://doi.org/10.1136/bjsm.2006.029652

Valente-dos-Santos, J.; Coelho-e-Silva, M.J.; Martins, R.A.; Figuiredo, A.J.; Cyrinho, E.S.; Sherar, L.B.; Vaeyens, R.; Huijgen, B.C.H.; Elferink-Gemser, M.T.; and Malina, R.M. (2012). Modelling developmental changes in repeated-sprint ability by chronological and skeletal ages in young soccer players. International Journal of Sports Medicine, 33(10), 773-780.

https://doi.org/10.1055/s-0032-1308996

Williams, A.M. (2000). Perceptual skill in soccer, Implications for talent identification and development. Journal of Sports Science, 18(9), 737-750.

https://doi.org/10.1080/02640410050120113 